\title{
The Effect Of Motivation, Organizational Commitment And Job Satisfaction Towards Organizational Citizenship Bahavior (OCB) at Headquarters of The Entrepreneurship Training Agency, Dili-Timor-Leste
}

\author{
Maria Cárceres Pinto Soares ${ }^{1}$ I Gede Riana ${ }^{2}$ Augusto da Conceição Soares ${ }^{3}$ \\ Master's Program, Institute of Business (IOB), Timor-Leste ${ }^{1}$ \\ Faculty of Economics and Business UDAYANA University, Bali, Indonesia ${ }^{2}$ \\ Master'sProgram, Institute of Business (IOB), Timor-Leste ${ }^{3}$
}

\begin{abstract}
This study aims to determine: (1) The influence of motivation on the Organizational Citizenship Behavior of employees of the Entrepreneurship Training Agency, Dili, Timor-Leste. (2) The Effect of Organizational Commitment on Organizational Citizenship Behavior of Employees of the Entrepreneurship Training Agency, Dili Timor-Leste. (3) The Effect of Job Satisfaction on Organizational Citizenship Behavior of Employees of the Entrepreneurship Training Agency, Dili, Timor-Leste. The population in this study amounted to 33 employees who work at the Head Office of the Entrepreneurship Training Agency, Dili, Timor-Leste by determining the saturated sample of the sample with the highest to lowest respondent rates. The findings of this study are to obtain the highest average value is $42.4 \%$. Then the lowest value obtained a value of $0.001 \%$.

Keywords: Motivation, Organizational Commitment, Job Satisfaction, and Organizational Citizenship Behavior (OCB).
\end{abstract}

\section{INTRODUCTION}

Human resources are very important in companies and organizations because of the effectiveness and success of a company organization and company depending on the quality and performance of human resources.

Other resources cannot be used, let alone managed to produce a product, without human resources, but in reality, many organizations do not realize the importance of human resources for organizational survival (Muchlis and Majid, 2017).

According to the theorists Putra and Supartha, 2017, it is stated that OCB is very important to support the effectiveness of organizational functions, especially in the long term. 
In Muhammad's theory, which was revised in the book in the Dinnis M. Organ Theory, which was posted on March 16, 2019, from the revised book, it states that the notion of organizational citizenship behavior (OCB), the phenomenon of organizational citizenship behavior / Organizational Citizenship Bahavior OCB, is when individuals voluntarily help people others without reward.

Definition of Work motivation Work motivation is one of the factors that determine a person's performance, the size of the influence of work motivation on a person's performance depends on how much motivation intensity is given. Hamzah B. Uno (2012: 71). Thus it can be said that motivation is basically a mental condition that encourages action (action or activity) and provides strength that leads to the achievement of needs.

If employees who have high commitment have low absentee scores and have a longer working period and tend to work harder and show better performance. A person's commitment to the organization is one of the guarantees for maintaining the continuity of the organization (Hoke et al. 2018). The definition of job satisfaction is a pleasant or unpleasant emotional state in which employees view their work. Job satisfaction has an important meaning for both employees and the organization, especially because this can create a positive situation for the work environment in the organization (Prabandewi and Indrawati, 2016 ). Research conducted by Huang et al. (2012) on nurses in Taiwanese hospitals proved that satisfaction can increase OCB. This statement is made clear by the research from Pratama and Utama (2017) which shows that employees who get job satisfaction will show their sense of volunteering to do work outside their job description. Above shows that from the gender of the most respondents were male, amounting to 14 people (42\%) compared to women, namely 19 people (58\%). In terms of age, most respondents were aged over 31- 40 years with 27 people (82\%), followed by respondents aged 41-50 years, namely 3 people $(9 \%)$. In terms of education, the most respondents were at the level of undergraduate education (S1) with a total of 20 people $(61 \%)$, then the respondents with a D3 education level were 6 people (18\%), high school with a total of 5 people $(15 \%)$ and those who lastly, the master's education level was 2 people (6\%). Tests on 33 respondents to determine the validity and reliability in this study. The results of the validity and reliability test recapitulation in this study. The table above shows that research instrument used has validity value $>30$ and a reliability value $>60$ so that the items in this study are said to have met the validity and reliability criteria and are declared valid and reliable. 


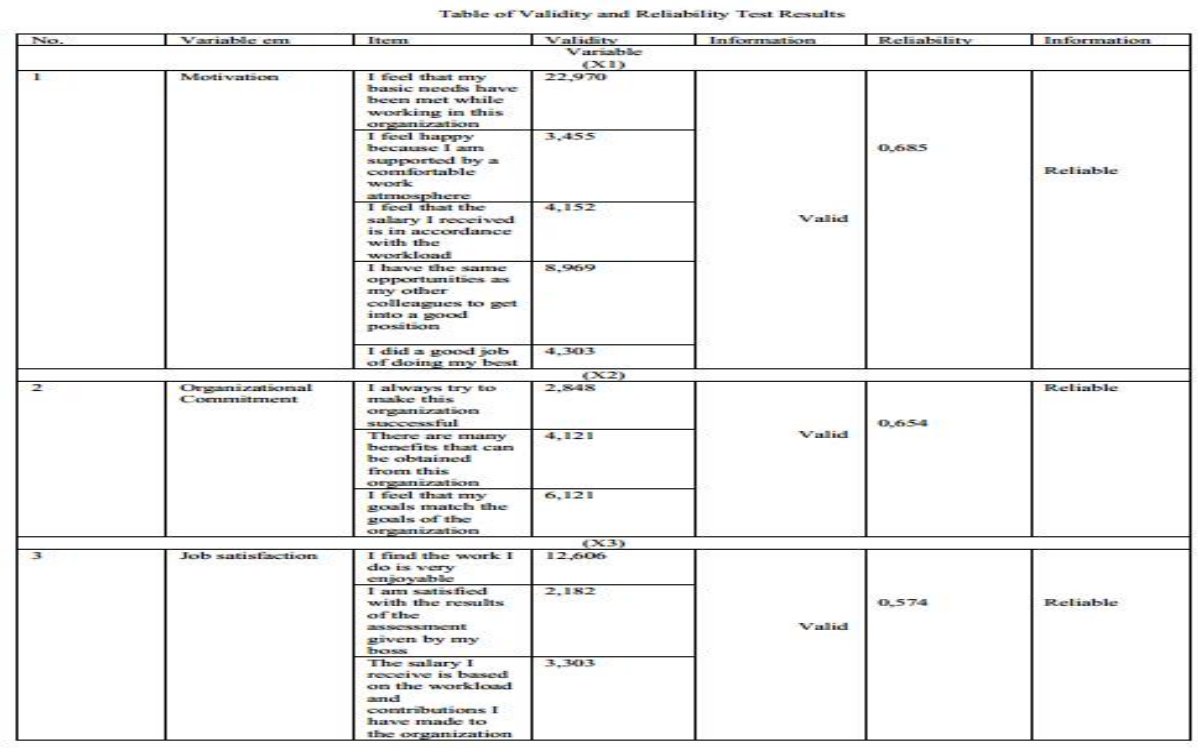

Work motivation is one of the factors that determine a person's performance, the size of the influence of work motivation on a person's performance depends on how much motivation intensity is given. Hamzah B. Uno (2012: 71). Thus, it can be said that motivation is basically a mental condition that encourages action (action or activity) and provides strength that leads to the achievement of needs, to give satisfaction or to reduce imbalance. Therefore motivation is related to the influence of behavior, strength of reaction and persistence of behavior as well as due to the implementation of behavior in a certain way. Work motivation is one of the factors that determine a person's performance, the size of the influence of work motivation on a person's performance depends on how much motivation intensity is given. Hamzah B. Uno (2012: 71). Thus, it can be said that motivation is basically a mental condition that encourages action (action or activity) and provides strength that leads to the achievement of needs, to give satisfaction or to reduce imbalance. There is a definition that states that motivation is related to. behavioral influence, reaction force (meaning work effort), after an employee has decided on the course of actions, and the persistence of the behavior, or how long the person has continued to carry out the behavior in a particular way. The description of the employee motivation variables can be explained in the following table: 


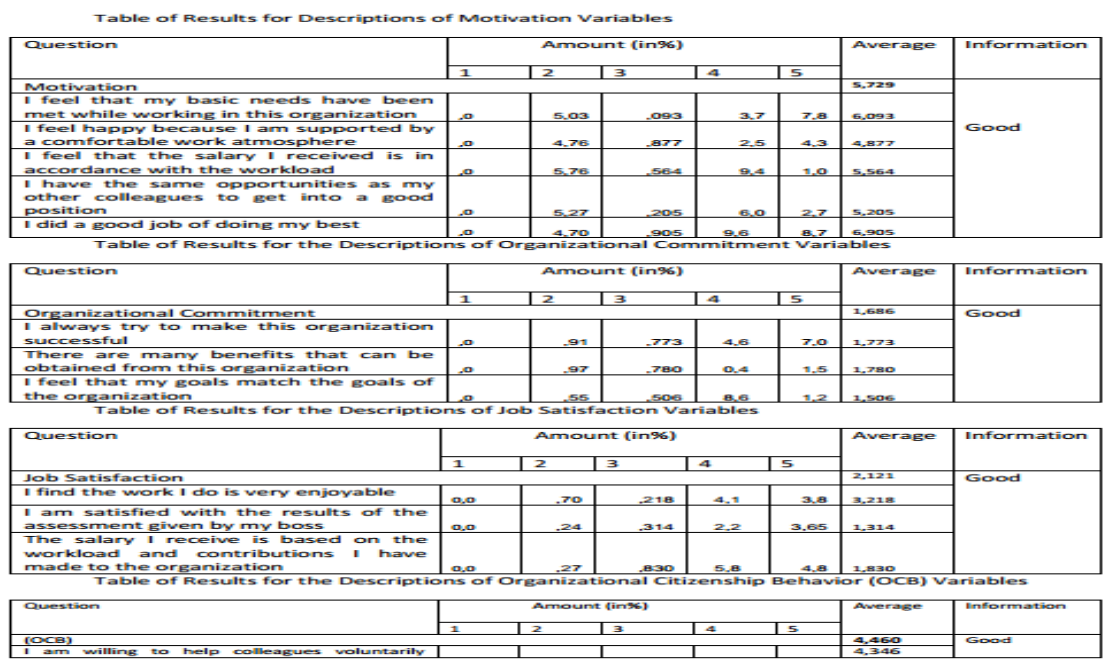

Overall, it has an average motivation of 5.729, organizational commitment of 1.686, job satisfaction of 2.121 and organizational citizenship behavior (OCB) of 4.460, each percentage is in the Very good category. The following is a theoretical framework
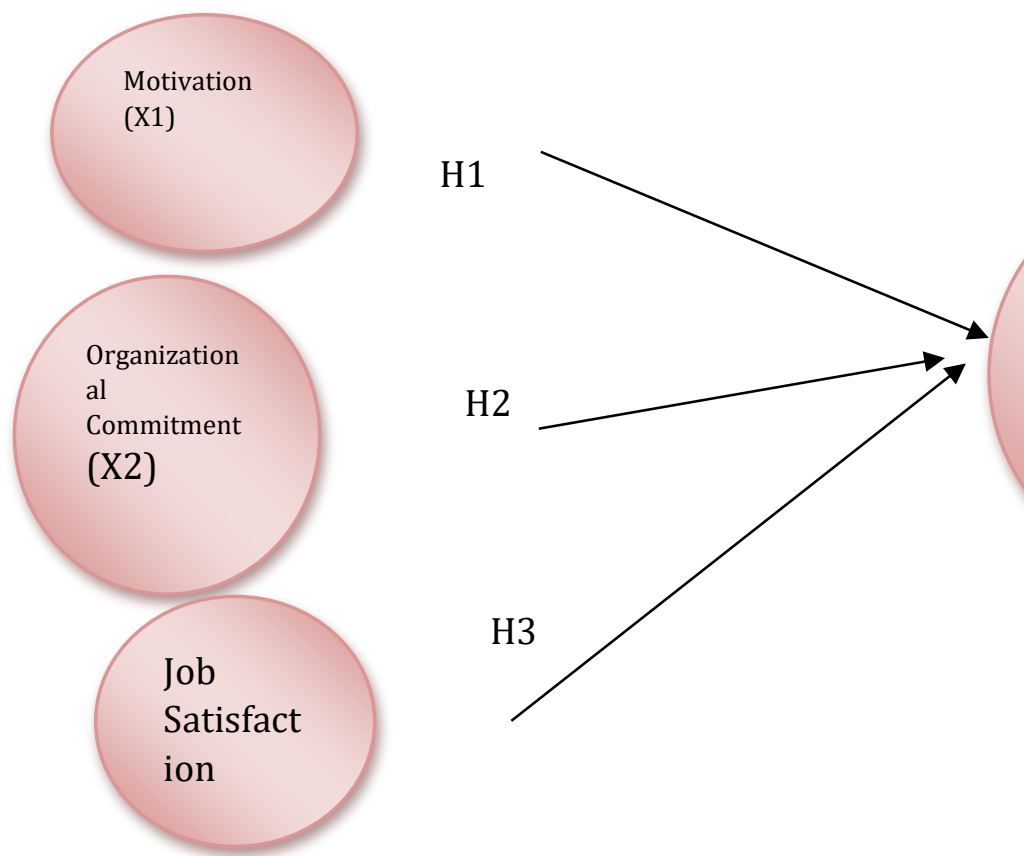

Organizational Citizenship Behavior (OCB)

$(\mathrm{Y})$

Source: Previous studies developed for this study.

Hypothesis Testing Results, in this study using multiple linear regression analysis to test the hypothesis using SPSS software. To test and analyze the research hypotheses that have been stated 
previously. Before conducting the analysis, first the empirical research model is tested or evaluated. The results of the analysis of the empirical research model using the SPSS analysis tool produce the following.

Testing Hypothesis 1: The influence of motivation on Organizational Citizenship

\section{Behavior (OCB)}

Hypothesis 1 states that motivation has a significant positive effect on organizational citizenship behavior (OCB) of employees. The coefficient test results show that motivation towards organizational citizenship behavior (OCB) shows a significant positive relationship with value multiple linear regression analysis of 0.076 with a p-value of 0.001 . This meaning that the better the application of human resource management practices will help improve employee performance.

Testing Hypothesis 2: The effect of organizational commitment on Organizational

\section{Citizenship Behavior (OCB)}

Hypothesis 2 states that organizational commitment has a significant positive effect on organizational citizenship behavior (OCB) of employees. The coefficient test results show that between organizational commitment to organizational citizenship behavior (OCB) shows a significant positive relationship with multiple linear regression analysis of 0.424 with a p-value of 0.001. This means that the better organizational commitment will help increase organizational citizenship behavior (OCB) of employees.

Testing Hypothesis 3: Effect of job satisfaction on Organizational Organization Behavior

(OCB)

Hypothesis 3 states that job satisfaction has a significant positive effect on organizational citizenship behavior (OCB) of employees. The coefficient test results show that between job satisfaction and organizational citizenship behavior (OCB) shows a significant positive relationship with value multiple linear regression analysis of 0.019 with a p-value of 0.001 . This means that the better the application of job satisfaction will help increase organizational citizenship behavior (OCB) of employees.

\section{RESEARCH METHODS}

This type of research uses explanatory research, namely the explanation of the relationship between variables through testing the hypotheses proposed in the study. The model used is 
causality, namely research that aims to analyze the causal relationship between 2 or more variables. Furthermore, this study was conducted to analyze the effect of organizational motivation, organizational commitment and job satisfaction on organizational citizenship behavior (OCB). In this study, the research objects were employees at the headquarters of the entrepreneurship training agency in Dili, Timor-Leste. This research was conducted from 7 November 2019 to 17 January 2020. Population is a generalization area consisting of: objects / subjects that have certain qualities and characteristics determined by researchers to be studied and then draw conclusions (Sugiyono, 2014). The sample is all employees of the Head Office of the Entrepreneurship Training Agency in Dili, Timor-Leste, namely 33 people. To support this research and obtain the required data, the type of data used is primary data which is taken directly from primary sources using a questionnaire.

\section{RESULTS AND DISCUSSION}

Motivation has a positive effect on organizational citizenship behavior This research was carried out inseparable from the results of previous research studies that have been conducted as a comparison and study. The results of the research used as comparisons cannot be separated from the research topic, namely the influence of motivation, organizational commitment and job satisfaction on organizational employee citizenship behavior. The results of hypothesis testing state that motivation has a significant positive effect on organizational citizenship behavior (OCB) of employees. This indicates that there is motivation, the better organizational employees are felt. Motivation is measured using the work motivation indicators provided in accordance with the provisions on employment of employees at the Timor-Leste Entrepreneurship Training Agency the results given to (X1.1) are 6,093 regarding the question I feel that my basic needs have been met while working in this organization. Then the results given by (X1.2) were 4,877 about me feeling happy because they were supported by a comfortable working atmosphere, then the results given in (X1.3) were 5.564 about me having the same opportunity as my other colleagues to reach the position which is good, while the results given at (X1.4), amounting to 5.205 about me having the same chance as my other colleagues to achieve a good position, there are also results given at (X1.5) of 6,905 about me doing work I'm good at realizing my best. Diatmika and Suwandana (2016) conducted another study on 42 employees at Alam Puri Villa Art Museum Resort and Spa Penatih Denpasar showing that work motivation has a positive and significant effect on OCB.But 
what is measured using the organizational commitment indicator given in accordance with the provisions of employee employment in the Timor-Leste Entrepreneurship Training Agency the results given in (X2.1) are 1.773 about the question I always try to make this organization successful, then the results given by (X2 .2) of 1,780 about the many benefits that can be obtained from this organization, followed by the results given in (X2.3) of 1.506 about me feeling that my goals are in accordance with organizational goals. Whereas measured using the job satisfaction indicator given in accordance with the provisions of employee employment at the Timor-Leste Entrepreneurship Training Agency the results given in (X3.1) are 3,218 about the question I feel the work I do is very pleasant, then the results given to (X3.1) are 3,218. X3.2) of 1,314, I am satisfied with the results of the assessment given by my boss, while the results given in (X3.3) are 1,830 regarding my salary received based on the workload and contributions I have made to the organization. Sucahya and Suana (2016) conducted a study entitled the effect of organizational commitment on OCB on 67 employees at the Denpasar City One Stop Integrated Licensing Service Agency (BPPTSP \& PM) and found that organizational commitment has a positive and significant effect on OCB. This statement is clarified by the research of Atmaja and Adnyani (2016) which states that employees who have organizational commitment will do not only the tasks that have become their obligations but will voluntarily do things that can be classified as extra efforts (extra effort). But what is measured using the indicator organizational citizenship behavior (OCB) which is given in accordance with the provisions of employee employment in the Timor-Leste Entrepreneurship Training Agency the results given to (Y1.1) are 4,346 about the question I am willing to help colleagues voluntarily without expecting anything in return., then the result is given at (Y1.2) of 5,281 about me maintaining good relations with colleagues, in order to avoid interpersonal problems, there are also results given at (Y1.3) of 4.209 about me being appropriate to the policies set by the organization, while the results given in (Y.1.4) of 3,760 about I am willing to carry out work beyond the assigned job description, but the results given in (X1.5) are 4,706 about me always participating in all activities held by the organization. Putra and Supartha (2017) conducted a study entitled the effect of job satisfaction on OCB on 52 employees at Green Garden Hotel Bali and found that job satisfaction had a positive and significant effect on OCB. Research conducted by Huang et al. (2012) on nurses in Taiwanese hospitals proved that satisfaction can increase OCB. This statement is made clear by the research from Pratama and Utama (2017) which 
shows that employees who get job satisfaction will show their sense of volunteering to do work outside their job description.

\section{CONCLUSIONS}

This research was conducted on 33 members of employees of the Entrepreneurship Training Agency, Dili Timor-Leste, a government institution that is engaged in training entrepreneurs in Timor-Leste. This head office is located on Jalan Fomento Mandatin by using telephone number 3310161, no. 18,. Researchers have collected information from the thirty respondents consisting of 14 men and 19 women. The majority of respondents mostly have an undergraduate degree, S2 respondents are 2 people and the others are diploma three and high school, while in terms of age nearly $82 \%$ are aged between 31-40 years, then aged 40-51 9\%, some are also aged $>516 \%$, but those aged between 26-30 researchers were 3\%. Human Resources are very important for the survival of an organization, both government and companies. Developed countries are always supported by the quality of human resources. Timor-Leste has a strategic development plan for 2011-2030 and has defined its vision of transforming a new Timor-Leste. And the results of the analysis concluded that the influence of motivation, organizational commitment and job satisfaction on employee organizational citizenship behavior (OCB) is:

1. Motivation has a significant positive effect on employee Organizational Citizenship Behavior. The coefficient test results show that there is a significant positive relationship with the value of multiple linear regression analysis of 0.256 with a p-value of 0.001 . This means that the better the motivation is done, the better the employee's Organizational Citizenship Behavior.

2. Organizational Commitment has a significant positive effect on the Organizational Citizenship Behavior of employees. The coefficient test results show that there is a significant positive relationship with the value of multiple linear regression analysis of 0.4 .24 with a p-value of 0.001 . This means that the better the motivation is done, the better the employee's Organizational Citizenship Behavior.

3. Job Satisfaction has a significant positive effect on employee Organizational Citizenship Behavior. The coefficient test results show that there is a significant positive relationship with the value of multiple linear regression analysis of 0.019 with a p-value of 0.001 . This means that the better the motivation is done, the better the employee's Organizational Citizenship Behavior. 


\section{Suggestion}

Based on the above conclusions, the suggestions that can be conveyed in this study are as follows: 1. Work motivation is one of the factors that determine a person's performance, the size of the influence of work motivation on a person's performance depends on how much motivation intensity is given.

2. Organizational commitment is a willingness to exert extra effort for the benefit of the organization, and a strong desire to maintain membership in the organization. Organizational commitment plays an important role in improving quality and employee productivity. The high commitment of employees is inseparable from the employees' trust in the good treatment of management towards them, namely the existence of a management approach to human resources as a valuable asset and not merely as a commodity that can be exploited at will. Every management of an organization must be required to increase growth and / or better progress from time to time. Because, commitment is the determination of the decision maker in achieving the goals that have been set.

3. Job satisfaction is a pleasant or unpleasant emotional state in which employees view their work. Job satisfaction has an important meaning for both employees and the organization, especially because this can create a positive situation for the work environment in the organization. Job satisfaction represents the negative and positive feelings of employees' perceptions of the work they face, namely a feeling of achievement and success at work, high job satisfaction implies that employees feel happy and comfortable with the conditions of the organization's environment and receive rewards from their hard work. . Job satisfaction shows a match between expectations and reality about his job. Satisfaction work also applies to individuals or groups. Job satisfaction has dominant dimensions, including: Leadership, competence for the attention faced, competence is closely related to job satisfaction, because each person has expertise in certain fields, management policies can affect employee satisfaction and dissatisfaction and show partiality to people. certain people will cause real jealousy and dissatisfaction. Compensation is a dominant factor, where compensation that pays attention to aspects of contribution and fair performance can lead to job satisfaction, appreciation, someone who feels valued in his work will lead to enthusiasm and job satisfaction. An employee's business that is not appreciated will have implications for other factors, such as low innovation and motivation, a conducive environment that will create a sense of comfort 
and fun for employees or members in carrying out their work, of course, can have implications for job satisfaction.

\section{Implications}

Research Implications, after looking at the discussion of research results, the implications can be categorized as follows:

Theoretical Implications. The theoretical implications obtained in this study are based on empirical studies and hypotheses obtained by several theoretical Panggali and Zulaicaha (2012), Suparta et al. (2013), Danendra da Mujiati (2016), Ardan et al. (2017), regarding work motivation, organizational commitment and job satisfaction on employee organizational citizenship behavior. Likewise, Muhammad's Theory, which was revised in the Book in Dinnis M. Organ's Theory, which was posted March 16, 2019, from the revised book, states that the phenomenon of organizational citizenship behavior / Organizational Citizenship Bahavior OCB, is when individuals voluntarily help others without reward. Practical implications, from this research it can be seen the level of approval from the Head of the Timor-Leste Entrepreneurship Training Agency, namely the Executive Director, to researchers to conduct research on 33 employee members who want to be investigated in organizations to pay attention to motivation, organizational commitment and job satisfaction towards organizational citizenship behavior. (OCB) and how these three things can contribute to the sustainability of the organization, especially in the aspect of employee motivation.

\section{REFERENCES}

Ahdiyana, M. 2011. Dimensions of Organizational Citizenship Behavior (OCB) in Organizational Performance. Journal of Applied Psychology, 8 (2), p. 1///Dinnis M. Organ in

Muhammad March 16, 2019, the phenomenon of organizational citizenship behavior / Organizational Citizenship Bahavior OCB.///Danendra, A A N B and Ni W. M. 2016. The Influence of Motivation, Compensation and Organizational Commitment to Organizational Citizenship Behavior (OCB). E-Journal of Management of Udayana University, 5 (10), pp. 62296259.///David McClelland in Anwar Prabu Mangkunegara (2011: 103), suggests six characteristics of people who have high achievement motives./////Hoke et al. 2018, high commitment has a low absentee value and has a longer working mass and tends to work harder and show better performance./////Hamzah B. Uno (2012: 71) Work Motivation is one 
of the factors that determines a person's performance.///Putra and Supartha (2017) tested the effect of job satisfaction on OCB on 52 employees at Green Garden Hotel Bali 10.////Suparta et al. (2013) stated that organizational commitment has a positive and significant effect on OCB/////S.P Hasibuan (2010: 100) human resource management (HRM) has good methods to motivate employees.//Wijaya, Ferry Jaya and Sutanto, Eddy Madiono. (2014). The Influence of Organizational Commitment and Employee Job Satisfaction on Organizational Citizenship Behavior (OCB) at Pt Xyz Surabaya.AGORA. 2 (2), page: 1-6. 